\title{
Label-free protein profiling of formalin-fixed paraffin-embedded (FFPE) heart tissue reveals immediate mitochondrial impairment after ionising radiation
}

\author{
Omid Azimzadeh ${ }^{a, *}$, Harry Scherthan ${ }^{b}$, Ramesh Yentrapalli, c, Zarko Barjaktarovic $^{a}$, \\ Marius Ueffing ${ }^{d, e}$, Marcus Conrad ${ }^{f}$, Frauke Neff ${ }^{g}$, Julia Calzada-Wack ${ }^{g}$, Michaela Aubele ${ }^{g}$, \\ Christian Buske ${ }^{h}$, Michael J. Atkinson ${ }^{a, i}$, Stefanie M. Hauck ${ }^{d, 1}$, Soile Tapio ${ }^{a, 1}$ \\ ${ }^{a}$ Helmholtz Zentrum München, German Research Center for Environmental Health, Institute of Radiation Biology, Neuherberg, Germany \\ ${ }^{b}$ Bundeswehr Institute of Radiobiology affiliated to the University of Ulm, Munich, Germany \\ ${ }^{\mathrm{c} C e n t r e ~ f o r ~ R a d i a t i o n ~ P r o t e c t i o n ~ R e s e a r c h, ~ D e p a r t m e n t ~ o f ~ G e n e t i c s, ~ M i c r o b i o l o g y ~ a n d ~ T o x i c o l o g y, ~ S t o c k h o l m ~ U n i v e r s i t y, ~ S t o c k h o l m, ~ S w e d e n ~}$ \\ ${ }^{\mathrm{d}}$ Helmholtz Zentrum München, German Research Center for Environmental Health, Research Unit Protein Science, Neuherberg, Germany \\ ${ }^{e}$ Centre of Ophthalmology, University Medical Centre, Tübingen, Germany \\ ${ }^{\mathrm{f} D Z N E}$, German Center for Neurodegenerative Diseases and Helmholtz Zentrum München, Institute of Developmental Genetics, Neuherberg, Germany

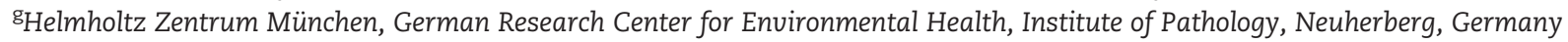 \\ ${ }^{\mathrm{h}}$ Institute of Experimental Cancer Research, University Hospital Ulm, Ulm, Germany \\ ${ }^{i}$ Department of Radiation Oncology, Klinikum rechts der Isar, Technical University of Munich, Munich, Germany
}

\section{A R T I C L E I N F O}

\section{Article history:}

Received 21 December 2011

Accepted 13 February 2012

Available online 23 February 2012

Keywords:

Label-free

Ionising radiation

Proteomics

Mitochondria

FFPE

\begin{abstract}
A B S T R A C T
Qualitative proteome profiling of formalin-fixed, paraffin-embedded (FFPE) tissue is advancing the field of clinical proteomics. However, quantitative proteome analysis of FFPE tissue is hampered by the lack of an efficient labelling method. The usage of conventional protein labelling on FFPE tissue has turned out to be inefficient. Classical labelling targets lysine residues that are blocked by the formalin treatment. The aim of this study was to establish a quantitative proteomics analysis of FFPE tissue by combining the label-free approach with optimised protein extraction and separation conditions.

As a model system we used FFPE heart tissue of control and exposed C57BL/6 mice after total body irradiation using a gamma ray dose of 3 gray. We identified 32 deregulated proteins $(p \leq 0.05)$ in irradiated hearts $24 \mathrm{~h}$ after the exposure. The proteomics data were further evaluated and validated by bioinformatics and immunoblotting investigation. In good agreement with our previous results using fresh-frozen tissue, the analysis indicated radiation-induced alterations in three main biological pathways: respiratory chain, lipid metabolism and pyruvate metabolism. The label-free approach enables the quantitative measurement of radiation-induced alterations in FFPE tissue and facilitates retrospective biomarker identification using clinical archives.
\end{abstract}

(c) 2012 Elsevier B.V. All rights reserved.

\footnotetext{
Abbreviations: Gy, Gray; Mw, molecular weight; O/N, overnight; TBI, total body irradiation.

* Corresponding author at: Helmholtz Zentrum München, German Research Center for Environmental Health, Institute of Radiation Biology, Ingolstaedter Landstrasse 1, 85764 Neuherberg, Germany. Tel.: +49 893187 3887; fax: +49 8931873378.

E-mail address: omid.azimzadeh@helmholtz-muenchen.de (O. Azimzadeh).

1 These authors contributed equally to the work.
} 


\section{Introduction}

For decades, pathologists have been using formalin-fixed, paraffin-embedded (FFPE) tissue for histological analysis due to its excellent performance and suitability for long-term storage. Clinical archives including data on diagnosis and outcome may provide information on biological pathways and cellular processes leading to disease, provided that suitable molecular technologies are available [1-3].

Proteomics analysis using FFPE material as an alternative to fresh-frozen tissue has recently been investigated [4-7]. Different methods of extraction and separation of proteins from FFPE samples have been established [8-11]. However, quantitative proteomic studies on archival material have been considered as an almost impossible task, primarily due to the harsh and irreversible fixation procedures and loss of integrity during prolonged storage. The formaldehyde fixation leads to a methylol modification, tagged mainly on lysine residues [11,12]. Most chemical labels used in quantitative proteomics also target lysine residues, leading to inefficient labelling of FFPE material [13-15].

Recently, non-labelling approaches have been suggested as an alternative for quantification of FFPE proteome profiles $[16,17]$. The few quantitative proteomic studies published so far have been performed using tumour FFPE tissues where areas of interest are easily distinguished and dissected [18,19], thereby reducing the complexity of the resultant proteome profile.

The aim of this study was to establish a quantitative proteomics work flow using the label-free approach [20] in a tissue where no discrete target area can be observed. We have shown previously that ionising radiation has both immediate and persistent effects on the murine cardiac proteome without causing any morphological changes in the heart [21,22]. Therefore, we used the cardiac tissue of sham- and total body irradiated C57BL/6 mice as a model system. We applied the optimised protein extraction and separation conditions for FFPE tissue previously developed by us for qualitative proteomics [11]. The analysis indicated radiation-induced impairment of the cardiac mitochondrial proteome. The proteomics data were further evaluated and validated by bioinformatics and immunoblotting investigation.

\section{Materials and methods}

\subsection{Materials}

Beta-octylglucoside, SDS, and ammonium bicarbonate were obtained from Sigma (St. Louis, MO); RapiGest from Waters (USA); acetone, acetonitrile, formic acid, and trifluoroacetic acid (TFA) from Roth (Karlsuhe, Germany); dithiothreitol (DTT), iodoacetamide, tris-(hydroxymethyl) aminomethane (Tris) and sequencing grade trypsin were obtained from Promega (Madison, WI); cyano-4-hydroxycinnamic acid was obtained from Bruker Daltonik (Bremen, Germany). All solutions were prepared using HPLC grade water from Roth (Karlsuhe, Germany).

\subsection{Animals}

Mice (C57BL/6) were purchased from Charles River Laboratories, Germany $\mathrm{GmbH}$. They were kept under standard conditions with food and water ad libitum (Altromin $\mathrm{GmbH}$, Lage, Germany). All animal experiments were performed in compliance with the German Animal Welfare Law and were approved by the institutional committee on animal experimentation and the government of Upper Bavaria (Certificate of the Regierung von Oberbayern, No. 211-2531-54/01). Animals were irradiated using a Gamma cell 40 equipment (upper source: Cs-134 and lower source: Cs-137) (Atomic Energy of Canada Limited, Ottawa). Heart tissue obtained from male C57BL/6 mice was used for all experiments. The animals were exposed at the age of 4 months to $3 \mathrm{~Gy}$ total body irradiation (TBI) with a single gamma-ray dose using a dose rate of $0.6 \mathrm{~Gy} / \mathrm{min}$. Control mice were sham irradiated. The mice were sacrificed by cervical dislocation $24 \mathrm{~h}$ after exposure; the hearts were rapidly removed and rinsed with phosphate buffered saline to remove excess blood. A total number of 6 animals were used for this study.

\subsection{Tissue preparation}

Heart tissues were immediately fixed in $4 \%$ buffered formalin for $24 \mathrm{~h}$, dehydrated with a graded series of ethanol before embedding in paraffin. Blocks were stored in the dark at room temperature. The blocks were cut into $20 \mu \mathrm{m}$ sections after initial trimming to remove air exposed surfaces.

\subsection{Protein extraction}

Proteins were extracted as described before [11]; briefly, tissue sections ( $20 \mu \mathrm{m}$ thick, $80 \mathrm{~mm}^{2}$ wide) were placed on microscope slides and deparaffinised by incubating twice with xylene for $10 \mathrm{~min}$ at room temperature before rehydration in a graded series of ethanol (100\%, 95\% and $70 \%)$ for $10 \mathrm{~min}$ each. The tissue sections were scraped from the slides, washed with $0.5 \%$ betaoctylglucoside and resuspended in buffer containing $20 \mathrm{mM}$ Tris-HCl, pH 8.8, 2\% SDS, 1\% beta-octylglucoside, $200 \mathrm{mM} \mathrm{DTT}$, and $200 \mathrm{mM}$ glycine. The extraction buffer contained protease inhibitor cocktail according to manufacturer's instructions (Roche Diagnostics).

All samples were incubated in the extraction buffer at $100{ }^{\circ} \mathrm{C}$ for $20 \mathrm{~min}$, and at $80^{\circ} \mathrm{C}$ for $2 \mathrm{~h}$ with shaking. The extracts were centrifuged for $30 \mathrm{~min}$ at $14,000 \mathrm{~g}$ at $4^{\circ} \mathrm{C}$. The protein extract was precipitated with the $2 \mathrm{D}$ clean up kit (GE Healthcare) following the manufacturer's instructions. The pellets were resuspended in Tris buffer in triplicate and protein quantification was done with both the Bradford method and 2D Quant Kit (GE Healthcare). All experiments were done with three biological replicates.

\subsection{Protein separation and mass spectrometry}

$100 \mu \mathrm{g}$ of protein extract from control and irradiated FFPE tissue was solubilised in SDS-PAGE sample buffer, and separated by $8 \%$ SDS-PAGE under reducing conditions before staining with Coomassie Brilliant Blue G-250.

The gel was cut horizontally into 5 equidistant fractions before the lanes were separated. All resultant gel slices were subjected to in-gel tryptic digestion as described previously [11] and peptides were eluted from the gel by two consecutive extractions with $50 \%$ acetonitrile (ACN)/0.5\% trifluoroacetic acid (TFA) and 100\% ACN/0.5\% TFA and vacuum dried. 
Peptides were solved directly before LC-MS/MS analyses in $2 \%$ ACN/0.5\% TFA and separated by reversed phase chromatography (PepMap, $15 \mathrm{~cm} \times 75 \mu \mathrm{m}$ ID, $3 \mu \mathrm{m} / 100 \AA \AA$ pore size, LC Packings) operated on a nano-HPLC (Ultimate 3000, Dionex) with a nonlinear 170 min gradient using $2 \%$ acetonitrile in $0.1 \%$ formic acid in water (A) and $0.1 \%$ formic acid in $98 \%$ acetonitrile (B) as eluents with a flow rate of $250 \mathrm{~nL} / \mathrm{min}$. The gradient settings were subsequently: 0 to $140 \mathrm{~min}$ : between $2 \%$ and $5 \%$ to $31 \% \mathrm{~B}$; 140 to $154 \mathrm{~min}$ : $31 \%$ to $95 \% \mathrm{~B}$; 145 to $150 \mathrm{~min}$ : constant at $95 \% \mathrm{~B}$; 150-155 min $95 \%$ to $5 \%$ B.

The nano-LC was connected to a linear quadrupole ion trapOrbitrap mass spectrometer (LTQ Orbitrap XL, ThermoFisher, Bremen, Germany) equipped with a nano-ESI source. The mass spectrometer was operated in the data-dependent mode to automatically switch between Orbitrap-MS and LTQ-MS/MS acquisition. Survey full scan mass spectra (from $\mathrm{m} / \mathrm{z} 300$ to 1500) were acquired in the Orbitrap with a resolution of $\mathrm{R}=60,000$ at $\mathrm{m} / \mathrm{z} 400$ (after accumulation to a target of 1,000,000 charges in the LTQ-MS/MS). This method allowed up to 10 of the most intense ions to be isolated sequentially, depending on signal intensity, for fragmentation on the linear ion trap using collision-induced dissociation at a target value of 100,000 ions. High resolution MS scans in the Orbitrap and MS/MS scans in the linear ion trap were performed in parallel. Target peptides already selected for MS/MS were dynamically excluded for $30 \mathrm{~s}$. General mass spectrometry conditions were: electrospray voltage from $1.25 \mathrm{kV}$ to $1.4 \mathrm{kV}$; no sheath or auxiliary gas flow. Ion selection threshold was 500 counts for MS/MS, and an activation Q-value of 0.25 and activation time of $30 \mathrm{~ms}$ were applied for MS/MS

\subsection{Label-free peptide quantification}

The acquired spectra (Thermo raw files) were loaded into the Progenesis LC-MS software (version 3.0, Nonlinear) and labelfree quantification was performed as described before [20]. Briefly, for each pre-fraction from the SDS-PAGE, the profile data of the MS scans as well as MS/MS spectra were transformed to peak lists with Progenesis LC-MS using a proprietary algorithm and then stored in peak lists comprising $\mathrm{m} / \mathrm{z}$ and abundance. One sample was set as a reference, and the retention times of all other samples within the experiment were aligned ( 3 to 5 manual landmarks, followed by automatic alignment) to create maximal overlay of the two-dimensional feature maps. At this point, features with only one charge or more than 7 charges were masked and excluded from further analyses and all remaining features were used to calculate a normalisation factor for each sample that corrects for experimental variation. Samples were then allocated to their experimental group (control or irradiated). For quantification, all unique peptides (with Mascot score $\geq 30$ and $p<0.01$, see below) of an identified protein were included and the total cumulative abundance was calculated by summing the abundances of all peptides allocated to the respective protein. No minimal thresholds were set for the method of peak picking or selection of data to use for quantification. Statistical analysis was performed using the "between subject design" and $p$-values were calculated by a repeated measures analysis of variance (ANOVA) using the sum of the normalised abundances across all runs. After processing of all samples from the pre-fractionation, the quantification files were merged into a complete data set.

\subsection{Database search and protein identification}

MS/MS spectra were exported from the Progenesis LC-MS software as Mascot Generic file (mgf) and used for peptide identification with Mascot (version 2.2) in the Ensembl database for mouse (Mus musculus; NCBIM37.64) downloaded from ftp://ftp.ensembl. org/pub/release-64/fasta/mus_musculus/pep/ containing a total of 54,576 sequences. Following search parameters were used: $10 \mathrm{ppm}$ peptide mass tolerance and 0.6 Da fragment mass tolerance, one missed cleavage was allowed, carbamidomethylation (C) was set as fixed modification and oxidation (M), deamidation $(\mathrm{N}, \mathrm{Q})$ as well as hydroxymethylation $(\mathrm{N}, \mathrm{K}, \mathrm{R}, \mathrm{H})$ were allowed as variable modifications. Mascot integrated decoy database search calculated a false discovery of $\leq 0.7 \%$ when searching was performed on the concatenated mgf files with an ion score cut-off of 30 and a significance threshold of $p \leq 0.01$. Only peptides with ion scores of 30 and above as well as proteins with at least one unique peptide ranked as top candidate (bold red in Mascot) were considered and re-imported into Progenesis LC_MS software. A total of 11583 peptides used for Mascot search (features) were identified. All protein identifications with at least two peptides and all identified peptides are listed in supplementary tables S1 and S2.

\subsection{Immunoblot analysis}

Proteins separated by SDS-PAGE were transferred to nitrocellulose membranes (GE Healthcare) using a TE 77 semidry blotting system (GE Healthcare) at $1 \mathrm{~mA} / \mathrm{cm}$ for $1 \mathrm{~h}$. The membranes were blocked using 3\% BSA in PBS, pH 7.4, for $1 \mathrm{~h}$ at room temperature, washed three times in $10 \mathrm{mM}$ Tris- $\mathrm{HCl}, \mathrm{pH} 7.4,150 \mathrm{mM}$ $\mathrm{NaCl}$ for $5 \mathrm{~min}$ and incubated $\mathrm{O} / \mathrm{N}$ at $4{ }^{\circ} \mathrm{C}$ with primary antibodies using dilutions recommended by the manufacturer. After washing three times, the blots were incubated with either horseradish peroxidase-conjugated or alkaline phosphatase-conjugated antimouse, anti-rabbit or anti-goat secondary antibody (Santa Cruz Biotechnology) for $2 \mathrm{~h}$ at room temperature and developed using the ECL system (GE Healthcare) or 1-step ${ }^{\text {TM }}$ NBT/BCIP method (ThermoFisher) following standard procedures.

\subsection{Pathway and functional correlation analysis}

\subsubsection{Gene Ontology (GO) analysis}

The differentially expressed proteins in all samples were categorised using the PANTHER bioinformatics tool (http://www. pantherdb.org) [23] and Database for Annotation, Visualization, and Integrated Discovery (DAVID; http://www.david.niaid.nih. gov). Gene ontology (GO) categories "molecular function", "cellular component" and "biological process" were analysed [24].

\subsubsection{Protein-protein interaction and signalling network}

The analyses of protein-protein interaction and signalling networks were performed by the software tool INGENUITY Pathway Analysis (IPA) (INGENUITY System, http://www. INGENUITY.com). IPA is a knowledge database generated from peer-reviewed scientific publications that enables discovery of 
highly represented functions and pathways $(p<0.001)$ from large, quantitative data sets [25]. Pathway assignment was done using the Reactome database (http://www.reactome.org) [26].

\section{Results}

\subsection{Protein quantification and identification}

In order to evaluate the technical variability of mass spectrometry runs of label-free peptide quantifications of FFPE samples, we first analysed an aliquot of one control sample by repetitive LC-MS/MS runs using four replicates. After alignment of all peptide intensities and identification of respective proteins, the cumulative intensities of all proteins were plotted against their counterpart in the technical replicates (Supplementary Fig. 1). The resulting scatter plots showed that all four replicates were linearly related, with a slope of the regression line close to 1 (between 0.91 and 1.13). The coefficient of determination $\left(\mathrm{R}^{2}\right)$ indicated a high linearity between the replicates $\left(R^{2}>0.99\right.$ for all comparisons). This linearity was also found when proteins identified by only one peptide were included (Supplementary Fig. 1, panels A, C and E), indicating a high reproducibility of the LC-MS/MS runs. The mean coefficient of variation (CV) for technical replicates was $8.0 \%$ for all identified proteins and $6.5 \%$ for proteins identified by two or more peptides.

Following the protein digestion and whole label-free quantification [20] using three biological replicates, a total number of 544 proteins were identified, of which 357 (65.6\%) were identified with at least 2 unique peptides. All proteins and peptides with statistical details are listed in Supplementary Tables S1 and S2. For proteins identified by 2 or more peptides, the mean CVs were $37.1 \%$ and $50.1 \%$ for control and irradiated samples, respectively. If proteins identified with only one peptide were included the mean CVs were $47.2 \%$ and $58.8 \%$ for control and irradiated samples, respectively. When all quantifications were grouped according to their regulation factor (fold change), the resulting histogram (Supplementary Fig. 2A) showed a near to normal distribution with a slight shift of the maximum towards negative values (log2 ratio of control/irradiated). When the log2 fold changes of the ratios (control/irradiated) were plotted against the -log10 of the $p$-values, the resulting volcano plot showed a typical V-shape (Supplementary Fig. 2B).

A total of 32 proteins were found to be significantly differentially expressed between control and irradiated samples using the following criteria: $p$-value $\leq 0.05 ; \pm 1$. 3 -fold regulation, identification by at least 2 unique peptides. Two proteins were up-regulated and 24 proteins were down-regulated in irradiated samples (Table 1). Five differentially expressed proteins quantified by single unique peptides ( $\mathrm{Y}$ binding protein 1, dystroglycan, methylmalonyl-CoA mutase, paxillinassociated protein with ARF GAP activity 3 and $\mathrm{NADH}$ ubiquinone oxidoreductase chain 3) were further validated by immunoblotting before being included in the final list of regulated proteins (Table 1). The respective MS/MS spectra with ion tables are given as supplemental information (Supplementary Fig. 3-7).

\subsection{Profiling of the deregulated proteins}

All significantly differentially expressed proteins (Table 1) were classified using GO categories (cellular components, molecular function and biological processes) with the PANTHER bioinformatics tool (http://www.pantherdb.org) [23]. Differentially expressed proteins grouped according to molecular functions are shown in Fig. 1A. Proteins with oxidoreductase activity represented the largest group. The GO analysis of biological processes indicated that the deregulated proteins were mainly involved in lipid, carbohydrate, phosphate and nucleic acid metabolism as well as molecular transport (Fig. 1B). The GO cellular compartment analysis showed that most deregulated proteins belonged to the mitochondrial proteome. Functional annotation clustering analysis using the DAVID software (http://www.david.niaid.nih.gov) [24] showed that the proteins belonged to different mitochondrial compartments such as membranes, electron transport machinery, matrix and channels (Fig. 1C). Furthermore, radiation-induced changes affected the proteins involved in oxidative phosphorylation such as NADH dehydrogenase, cytochrome c and succinate dehydrogenase.

\subsection{Pathway analysis}

Ingenuity Pathway Analysis (IPA) (http://www.INGENUITY. com) performed on all significantly differentially expressed proteins (Table 1), indicated that the majority of the deregulated proteins were involved in the networks "cardiovascular and metabolic disease" (IPA score =33), and "lipid metabolism" $($ IPA score $=25)$ (Supplementary Table 3A). The proteins forming the top-scoring networks were highly interconnected. Two most significant networks were merged in Fig. 2 showing three distinct clusters representing pyruvate metabolism, lipid metabolism and respiratory chain. In accordance with the GO analysis of biological processes, IPA analysis showed that the pathways "mitochondrial dysfunction", "oxidative phosphorylation", and "citrate cycle"/“pyruvate metabolism" were significantly affected by irradiation (Supplementary Table 3B).

An IPA toxicity analysis showed that the differentially expressed proteins were associated with radiation-induced cellular toxicity, mitochondrial dysfunction and cardiac necrosis (Supplementary Table 3C). Among the altered proteins categorised in different cardiotoxicity groups, the majority were involved in cardiac necrosis and cell death (Supplementary Table 3D).

An additional protein-protein interaction analysis was performed using the Reactome database (http://www.reactome. org). The analysis provided 25 additional annotated and curated pathways. The main pathways assigned to the deregulated proteins were consistent with those of the IPA analysis and are summarised in Table 1.

\subsection{Immunoblotting analysis}

Immunoblot analysis using antibodies against differentially expressed proteins was performed to validate the proteomics data. As shown previously by us [11] and others [16,27], immunoblot validation using FFPE samples is not always successful due to non-availability of the epitope caused by cross-linking. 
In the present study, the main bands, corresponding to full length proteins, were detected at the expected molecular weights (Fig. 3A, arrows), suggesting a partial release of the proteins from the cross-linked complex. However, some proteins appeared as multiple bands, indicating an irreversible cross-linking. (Fig. 3A; lanes e and f). This observation is consistent with the migration of proteins during the 1D electrophoresis at positions with unexpected molecular weights.

The amount of some deregulated proteins belonging to the mitochondrial respiratory chain was tested using a premixed cocktail containing antibodies against OXPHOS complexes (Fig. 3A; lane a). Signals detected in the region between 40 and $50 \mathrm{kDa}$ showed moderate differences in protein abundances of complexes III and V between the control and irradiated samples, whereas the other subunits (I, II and IV) were not detected. Immunoblot analysis showed that protein levels of cytochrome b c1 from complex III (CIII) and ATP synthase alpha from complex V (CV) were slightly but not significantly decreased $(p \leq 0.05$; Fig. 3A, lane a).

Whilst complex I (CI) proteins showed decreased levels of expression by label-free quantification but were not detected by the antibody cocktail, the CI subunits NDUFB6, ND4 and ND3 were additionally analysed by Western blotting (Fig. 3A; lanes $b$ and $c$ ). Consistent with the proteomics data, immunoblot analysis confirmed the lowered level of the NDUFB6, and ND4 proteins by 0.47 - and 0.64 -fold, respectively, in the irradiated samples ( $p \leq 0.05$; Fig. $2 \mathrm{~B}$ ). In the area of expected molecular weight of ND3, we detected no signals in either control or irradiated samples (data not shown). The alteration of several differentially expressed proteins that were identified by a single unique peptide was verified by immunoblotting. It showed a 0.73 -fold down-regulation in the expression level of methylmalonyl-CoA mutase (MC mut) protein in expected molecular weight confirming the proteomics data (Fig. 3A; lane d; B; $p \leq 0.05$ ).

In addition, the immunoblot analysis showed that the amounts of trifunctional enzyme subunit alpha (TFP) and mitofilin were lower by 0.56 and 0.6 , respectively, in the irradiated samples compared to the control samples (Fig. 3A; lanes e and $\mathrm{f} ; \mathrm{B} ; \mathrm{p} \leq 0.05)$, confirming the results of the proteomics analysis.

Immunoblot analysis also validated the up-regulation of dystroglycan alpha (DCG $\alpha$ ), paxillin-associated protein (Pap) and $\mathrm{Y}$ binding protein 1 (YB-1) that had been quantified as deregulated by a single unique peptide in the proteomics analysis. The level of dystroglycan alpha was significantly up-regulated by 1.54-fold (Fig. 3A; lane g; 3B). In contrast, no change was observed in dystroglycan beta amount between control and irradiated hearts by immunoblotting (Fig. 3A; lane h; 3B). Analysis confirmed an increased expression level of truncated $\mathrm{Yb}-1$ protein by 1.7-fold (lower band, indicated by a star) but no significant increase in the full length protein (upper band, indicated by the arrow) (Fig. 3A; lane I; 3B). The antibody detection of Pap showed an increase (1.37-fold) in irradiated compared to control samples (Fig. 3A, lane j; B; $p \leq 0.05$ ). Tubulin was used as a loading control in all experiments (Fig. 3A; lane k).

\section{Discussion}

Recent epidemiological data on exposed individuals clearly show that ionising radiation is a risk factor for cardiovascular disease [28-30]. However, the molecular mechanisms underlying the development of radiation-induced heart disease are not well understood so far. Proteomics is a powerful technology that can provide novel information about such biological mechanisms. In this study, we performed a quantitative proteomic analysis using FFPE cardiac tissue from exposed and nonexposed animals. Since the protein cross-linking during formaldehyde tissue fixation greatly reduces the number of free lysine residues, target molecules of classical protein labelling, we applied label-free quantitative proteomics to overcome this limitation [20].

The data presented here are in good agreement with the results from comparable fresh-frozen tissues [21]. In both cases, the most important canonical and toxic pathways affected by radiation were identical, namely mitochondrial dysfunction and oxidative phosphorylation. However, irreversible cross-linking may leave some radiation-affected proteins undetected. In the case of fresh-frozen samples [21], the number of significantly deregulated proteins was higher than in this study, being 52 and 32, respectively. Cardiac structural proteins that were found to be deregulated in irradiated freshfrozen samples [21] were not found significantly deregulated in irradiated FFPE samples. We suggest that structural proteins are more prone to remain in cross-linked protein complexes and therefore may be suboptimal for the FFPE proteome quantification, even using the label-free approach.

The sensitivity of the label-free proteomics approach and its suitability to analyse FFPE tissue is emphasised by the fact that the radiation dose used here ( $3 \mathrm{~Gy}$ ) does not cause any morphological alterations in the murine heart $24 \mathrm{~h}$ after the exposure [21].

The proteins were extracted from FFPE tissues of control and irradiated mouse hearts using our optimal buffer [11] before separation by LC MS/MS and quantification by label-free comparative analysis [20]. We identified 32 proteins differentially expressed in irradiated samples. Most of these were mitochondrial proteins involved in energy metabolism (Table 1). This is consistent with the radiation-induced impairment of mitochondrial structure and function that has been previously reported by us [21,22] and others [31-34].

\subsection{Respiratory chain and mitochondrial membrane and membrane-bound proteins}

We identified 34 of the 45 known subunits of Complex I. The levels of five subunits were significantly reduced after the exposure, indicating a marked radiation-induced alteration of this complex. We reported previously that both Complexes I and III are targets for radiation damage, resulting in increased ROS production and impaired mitochondrial respiratory capacity $[21,22]$. Here, we observed a significant down-regulation in the level of mitochondrial superoxide dismutase (Mn-SOD) that may be due to increased ROS production [31,32].

Furthermore, we found significant changes in the abundance of mitochondrial membrane and membrane-bound proteins such as mitofilin, integral membrane protein of Complex II, and different mitochondrial carrier proteins and channels. Down-regulated expression of cardiac channel proteins for $\mathrm{Ca}^{2}+$ and other ions, as well as metabolites such as aspartate, phosphate and ADP/ATP may contribute to an impaired 
Table 1 - Significantly differentially expressed proteins of cardiac FFPE quantified by label-free mass spectrometry. In addition, tubulin that was used as loading control for immunoblotting is given as the number 32 . The assigned pathways were provided using Reactome software (ww.reactome.org).

\begin{tabular}{|c|c|c|c|c|c|c|c|c|}
\hline & $\begin{array}{l}\text { UniProt } \\
\text { accession }\end{array}$ & Description & $\begin{array}{c}\text { Ratio } \\
\text { (control/ } \\
\text { irradiated) }\end{array}$ & $\begin{array}{l}\text { ANOVA } \\
(p)\end{array}$ & $\begin{array}{l}\text { Peptide } \\
\text { count }\end{array}$ & $\begin{array}{c}\text { Peptides } \\
\text { used for } \\
\text { quantitation }\end{array}$ & $\begin{array}{l}\text { Confidence } \\
\text { score }\end{array}$ & Biological function \\
\hline 1 & P51881 & $\begin{array}{l}\text { ADP/ATP translocase } \\
2\end{array}$ & 0.33 & 0.0093595 & 11 & 2 & 888 & ADP/ATP transport \\
\hline 3 & P52825 & $\begin{array}{l}\text { Carnitine O- } \\
\text { palmitoyltransferase } \\
\text { 2, mitochondrial }\end{array}$ & 0.58 & 0.0154218 & 5 & 5 & 214 & $\begin{array}{l}\text { Fatty acid, triacylglycerol, and } \\
\text { ketone body metabolism }\end{array}$ \\
\hline 4 & Q9D0M3 & $\begin{array}{l}\text { Cytochrome c1, heme } \\
\text { protein, } \\
\text { mitochondrial }\end{array}$ & 0.58 & 0.0491992 & 5 & 5 & 339 & $\begin{array}{l}\text { Respiratory chain electron } \\
\text { transport }\end{array}$ \\
\hline 5 & Q3TIE8 & $\begin{array}{l}\text { Dihydrolipoyl } \\
\text { dehydrogenase, } \\
\text { mitochondrial }\end{array}$ & 0.70 & 0.0007769 & 8 & 8 & 480 & $\begin{array}{l}\text { Pyruvate metabolism and citric } \\
\text { acid (TCA) cycle }\end{array}$ \\
\hline 6 & Q8BMF4 & $\begin{array}{l}\text { Dihydrolipoyllysine- } \\
\text { residue } \\
\text { acetyltransferase }\end{array}$ & 0.70 & 0.0124804 & 8 & 8 & 644 & $\begin{array}{l}\text { Pyruvate metabolism and citric } \\
\text { acid (TCA) cycle }\end{array}$ \\
\hline 7 & Q62165 & $\begin{array}{l}\text { Dystroglycan } \\
\text { (Dystrophin- } \\
\text { associated } \\
\text { glycoprotein 1) }\end{array}$ & 3.77 & 0.0076711 & 1 & 1 & 35 & Signal transduction/Receptor \\
\hline 8 & P63038 & $\begin{array}{l}\text { Heat shock protein } \\
60 \mathrm{kDa} \text {, mitochondrial }\end{array}$ & 0.68 & 0.0339778 & 18 & 18 & 1438 & Chaperonin \\
\hline 9 & Q2TPA8 & $\begin{array}{l}\text { Hydroxysteroid } \\
\text { dehydrogenase-like } \\
\text { protein } 2\end{array}$ & 0.77 & 0.0259087 & 2 & 2 & 98 & Lipid metabolism \\
\hline 10 & Q9D646 & $\begin{array}{l}\text { Keratin, type I cuticu- } \\
\text { lar } \mathrm{Ha} 4\end{array}$ & 6.56 & 0.0449691 & 2 & 2 & 101 & Structural protein \\
\hline 11 & P50446 & $\begin{array}{l}\text { Keratin, type II cyto- } \\
\text { skeletal 6A }\end{array}$ & 1.86 & 0.0059206 & 6 & 4 & 416 & Structural protein \\
\hline 12 & Q6PB66 & $\begin{array}{l}\text { Leucine-rich PPR } \\
\text { motif-containing } \\
\text { protein }\end{array}$ & 0.62 & 0.0363499 & 5 & 5 & 278 & Protein metabolism \\
\hline 13 & P16332 & $\begin{array}{l}\text { Methylmalonyl-CoA } \\
\text { mutase, } \\
\text { mitochondrial }\end{array}$ & 0.48 & 0.007615 & 1 & 1 & 42 & $\begin{array}{l}\text { Fatty acid, triacylglycerol, and } \\
\text { ketone body metabolism }\end{array}$ \\
\hline 14 & Q8BH59 & $\begin{array}{l}\text { Mitochondrial } \\
\text { aspartate glutamate } \\
\text { carrier } 1\end{array}$ & 0.43 & 0.0116975 & 10 & 7 & 578 & Carbohydrate metabolism \\
\hline 15 & Q8CAQ8 & Mitofilin & 0.48 & 0.0393568 & 9 & 9 & 638 & Mitochondrial membrane protein \\
\hline 16 & Q3UIU2 & $\begin{array}{l}\text { NADH dehydrogenase } \\
\text { [ubiquinone] } 1 \text { beta } 6\end{array}$ & 0.33 & 0.0077793 & 3 & 3 & 149 & $\begin{array}{l}\text { Respiratory chain electron } \\
\text { transport }\end{array}$ \\
\hline 17 & Q99LY9 & $\begin{array}{l}\text { NADH dehydrogenase } \\
\text { [ubiquinone] FE-S } \\
\text { protein } 5\end{array}$ & 0.47 & 0.0036318 & 2 & 2 & 133 & $\begin{array}{l}\text { Respiratory chain electron } \\
\text { transport }\end{array}$ \\
\hline 18 & P03899 & $\begin{array}{l}\text { NADH-ubiquinone } \\
\text { oxidoreductase chain } \\
3\end{array}$ & 0.33 & 0.0426123 & 1 & 1 & 73 & $\begin{array}{l}\text { Respiratory chain electron } \\
\text { transport }\end{array}$ \\
\hline 19 & P03911 & $\begin{array}{l}\text { NADH-ubiquinone } \\
\text { oxidoreductase chain } \\
4\end{array}$ & 0.23 & 0.018216 & 3 & 3 & 133 & $\begin{array}{l}\text { Respiratory chain electron } \\
\text { transport }\end{array}$ \\
\hline 20 & P03921 & $\begin{array}{l}\text { NADH-ubiquinone } \\
\text { oxidoreductase chain } \\
5\end{array}$ & 0.25 & 0.0007719 & 2 & 2 & 127 & $\begin{array}{l}\text { Respiratory chain electron } \\
\text { transport }\end{array}$ \\
\hline 21 & Q7SIG6 & $\begin{array}{l}\text { Paxillin-associated } \\
\text { protein with ARF GAP } \\
\text { activity } 3\end{array}$ & 2.58 & 0.044049 & 1 & 1 & 40 & Signal transduction \\
\hline 22 & Q8VEM8 & $\begin{array}{l}\text { Phosphate carrier } \\
\text { protein, } \\
\text { mitochondrial }\end{array}$ & 0.59 & 0.0326562 & 9 & 9 & 497 & Phosphate transport \\
\hline 23 & Q91ZA3 & $\begin{array}{l}\text { Propionyl-CoA } \\
\text { carboxylase alpha } \\
\text { chain, }\end{array}$ & 0.70 & 0.0062923 & 2 & 2 & 81 & $\begin{array}{l}\text { Fatty acid, triacylglycerol, and } \\
\text { ketone body metabolism }\end{array}$ \\
\hline
\end{tabular}




\begin{tabular}{|c|c|c|c|c|c|c|c|c|}
\hline & $\begin{array}{l}\text { UniProt } \\
\text { accession }\end{array}$ & Description & $\begin{array}{c}\text { Ratio } \\
\text { (control/ } \\
\text { irradiated) }\end{array}$ & $\begin{array}{l}\text { ANOVA } \\
(p)\end{array}$ & $\begin{array}{l}\text { Peptide } \\
\text { count }\end{array}$ & $\begin{array}{l}\text { Peptides } \\
\text { used for } \\
\text { quantitation }\end{array}$ & $\begin{array}{c}\text { Confidence } \\
\text { score }\end{array}$ & Biological function \\
\hline 24 & Q8BKZ9 & $\begin{array}{l}\text { Pyruvate } \\
\text { dehydrogenase } \\
\text { protein X component, }\end{array}$ & 0.52 & 0.0125367 & 2 & 2 & 121 & $\begin{array}{l}\text { Pyruvate metabolism and citric } \\
\text { acid (TCA) cycle }\end{array}$ \\
\hline 25 & E9Q401 & $\begin{array}{l}\text { Ryanodine receptor } 2 \\
\text { cardiac, Ca2+ release } \\
\text { channel }\end{array}$ & 0.50 & 0.0057643 & 3 & 3 & 110 & Calcium transport \\
\hline 26 & P07724 & $\begin{array}{l}\text { Serum albumin } \\
\text { precursor }\end{array}$ & 0.79 & 0.0168452 & 37 & 37 & 3564 & Lipid metabolism \\
\hline 27 & P16546 & Spectrin alpha chain & 0.75 & 0.0186663 & 4 & 3 & 171 & Structural protein \\
\hline 28 & Q9CZB0 & $\begin{array}{l}\text { Succinate } \\
\text { dehydrogenase } \\
\text { cytochrome b560 } \\
\text { subunit }\end{array}$ & 0.26 & 0.0106631 & 2 & 2 & 82 & $\begin{array}{l}\text { Pyruvate metabolism and citric } \\
\text { acid (TCA) cycle; Respiratory chain } \\
\text { electron transport }\end{array}$ \\
\hline 29 & Q9Z2I8 & $\begin{array}{l}\text { Succinyl-CoA ligase } \\
\text { [GDP-forming] } \\
\text { subunit beta }\end{array}$ & 0.73 & 0.0021744 & 3 & 3 & 144 & $\begin{array}{l}\text { Pyruvate metabolism and citric } \\
\text { acid (TCA) cycle }\end{array}$ \\
\hline 30 & P09671 & $\begin{array}{l}\text { Superoxide dismutase } \\
\text { [Mn], mitochondrial }\end{array}$ & 0.69 & 0.0337352 & 5 & 5 & 343 & Oxidoreductase metabolism \\
\hline 31 & Q8BMS1 & $\begin{array}{l}\text { Trifunctional enzyme } \\
\text { subunit alpha }\end{array}$ & 0.53 & 0.0077249 & 38 & 38 & 2856 & $\begin{array}{l}\text { Fatty acid, triacylglycerol, and } \\
\text { ketone body metabolism }\end{array}$ \\
\hline 32 & P62960 & $\begin{array}{l}\text { Y-box-binding protein } \\
1\end{array}$ & 2.37 & 0.0463156 & 1 & 1 & 75 & Nucleic acid metabolism \\
\hline 33 & P68369 & $\begin{array}{l}\text { Tubulin alpha-1A } \\
\text { chain }\end{array}$ & 1.02 & 0.789 & 1 & 13 & 885 & $\begin{array}{l}\text { Microtubule-based movement } \\
\text { (used as negative control) }\end{array}$ \\
\hline
\end{tabular}

mitochondrial function after radiation exposure. Deregulation of mitochondrial phosphate carrier protein and ADP/ ATP carrier protein has been associated with mitochondrial dysfunction under oxidative stress [35].

The proteomics and immunoblotting data indicated a decrease in the level of mitofilin in irradiated tissue. Mitofilin controls mitochondrial cristae morphology [36]. Down-regulation or depletion of mitofilin has been previously shown to result in increased flux of ions and metabolites, defective oxidative phosphorylation and enhanced production of reactive oxygen species (ROS) [37].

\subsection{Fatty acid metabolism}

Eleven deregulated proteins were directly or indirectly associated with fatty acid metabolism and the citric acid cycle (Table 1). The
A Molecular function

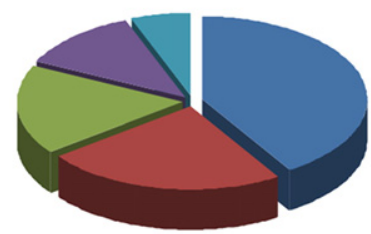

moxidoreductase activity (GO:0016491)(7;40\%) - transporter activity (GO:0005215)(4;24\%)

= structural molecule activity (GO:0005198)(3;18\%)

-ligase activity (GO:0016874)(2;12\%)

-receptor activity (GO:0004872)(1;6\%)
B Biological process

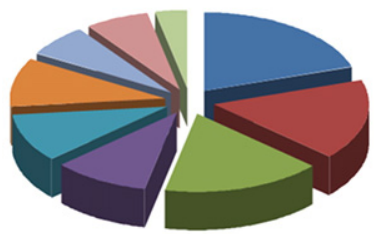

mlipid metabolic process (GO:0006629)(6;19\%) "small molecule transport (GO:0006810)(5;17\%) =carbohydrate metabolic process (GO:0005975)(5;17\%) - phosphate metabolic process (GO:0006796)(3;10\%) unucleic acid metabolic process (GO:0006139)(3;10\%) Incoenzyme metabolic process (GO:0006732)(3;10\%) protein metabolic process (GO:0019538)(2;7\%)

=xygen and reactive oxygen species metabolic process $(G 0: 0006800)(2 ; 7 \%)$

ferredoxin metabolic process (GO:0006124)(1;3\%)
C Cellular compartment

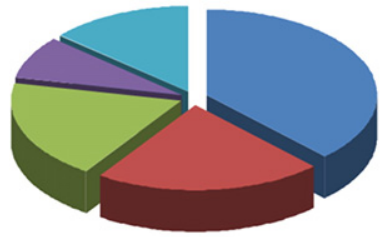

-mitochondrial membrane (GO:0031966)(14;37\%) -mitochondrial matrix (GO:0005759)(8;22\%) -mitochondrial respiratory chain complexes (GO:0070469)(7;19\%) mitochondrial substrate carrier (GO:0055085)(3;8\%) =cytoskeleton (GO:0005856)(5;14\%)

Fig. 1 - All significantly differentially regulated proteins (Table 1) were analysed for Go categories "Molecular function" (A), "Biological process" (B), and "Cellular compartment" using the PANTHER (http://www.pantherdb.org) and DAVID bioinformatics tools (http://www.david.niaid.nih.gov). The amount of deregulated proteins is indicated as percentage of the total amount of up- or down-regulated proteins at $24 \mathrm{~h}$. The number of deregulated proteins in each category and their percentage of the total number of proteins in the pie chart are indicated after the corresponding GO terms. 


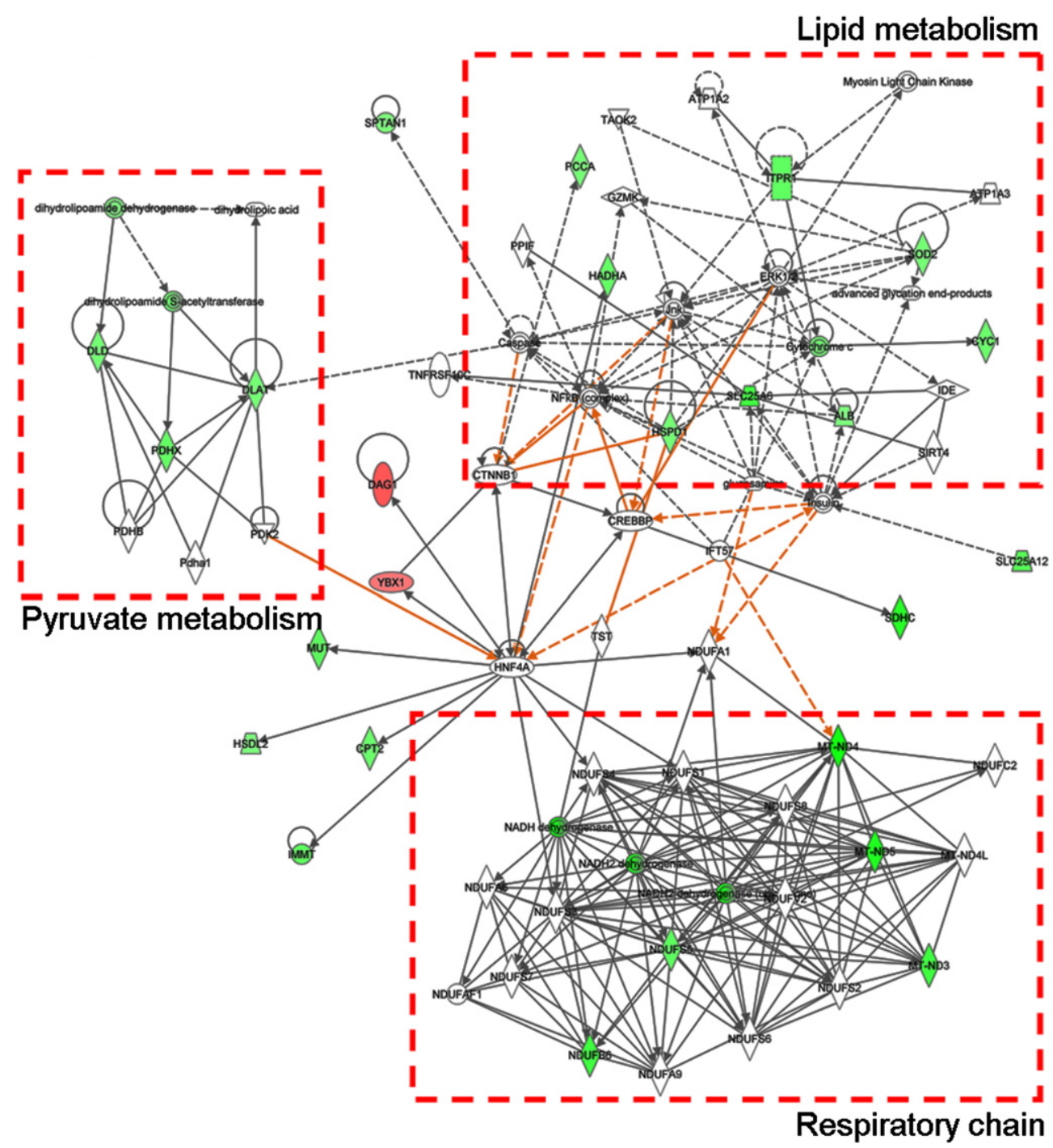

Fig. 2 - Graphical representation of the merged most significant protein networks using Ingenuity Pathway Analysis. All significantly deregulated proteins (Table 1) were imported into the Ingenuity Pathway Analysis. The up-regulated proteins are marked in red and the down-regulated in green. The nodes represent proteins that are connected with one or several arrows; the solid arrows represent direct interactions and the dotted arrows indirect interactions; direct and predicted protein interactions were searched for (http://www.Ingenuity.com).

majority of these proteins have been previously associated with heart failure and hypertrophy [38-41]. An impaired ability to oxidise fatty acids in hypertrophy has been shown to be caused by oxidative stress [42].

We observed a decrease in the abundance of mitochondrial trifunctional protein (TFP) subunit alpha that plays a central role in the fatty acid metabolism in the mitochondrial matrix [43]. Altered expression of TFP has been observed in cardiomyopathy, ischemia-reperfusion injury and acute heart failure [32,44,45]. Compared to the controls, irradiated samples also showed a lower expression level of methylmalonyl-CoA mutase (MCmut), a key protein in the degradation of cholesterol and odd-chain fatty acids producing succinyl-CoA [46]. A significant mitochondrial respiratory chain dysfunction and subsequent insufficient energy metabolism has been observed in patients with methylmalonyl-CoA mutase deficiency [47].

In accordance with our data, co-alteration in the abundance of proteins involved in mitochondrial electron transport chain (ETC) and fatty acid oxidation has been observed in different states of heart pathologies including pressure overloadinduced heart failure $[38,48]$ and ischemia-reperfusion injury $[49,50]$.

\subsection{Pyruvate metabolism}

We found down-regulation of three proteins associated with pyruvate metabolism, demonstrating a rapid radiation-induced alteration in the glucose oxidative pathway $[38,48]$. 
A
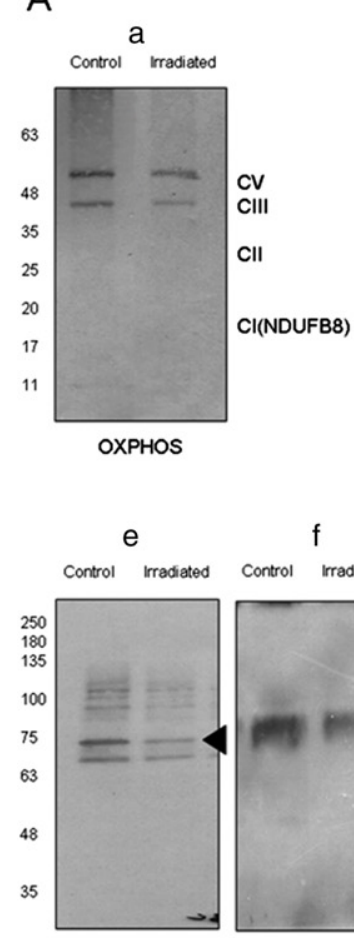

Mitofilin
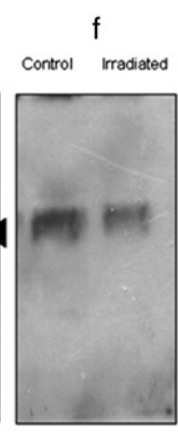

TFP b

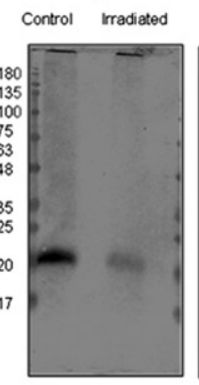

Cl(NDUFB6)
C

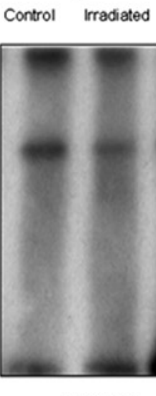

$\mathrm{Cl}(\mathrm{ND4})$ d

Control Irradiated

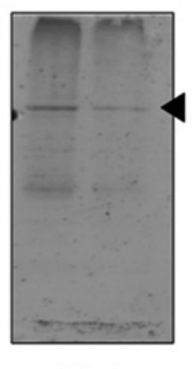

MCmut

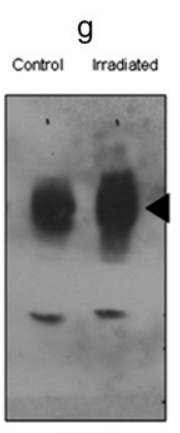

$D C G \alpha$ h

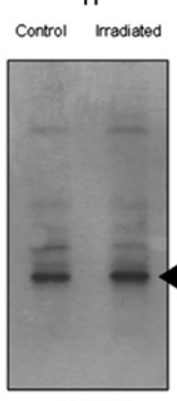

DCG $\beta$

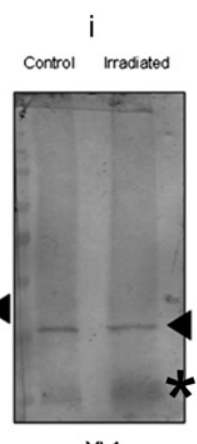

Yb1

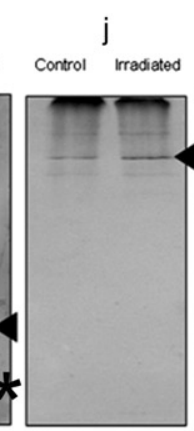

Pap k

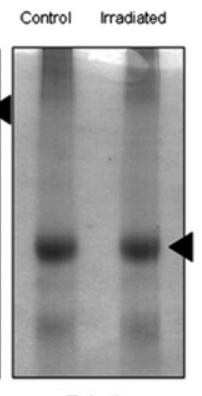

Tubulin

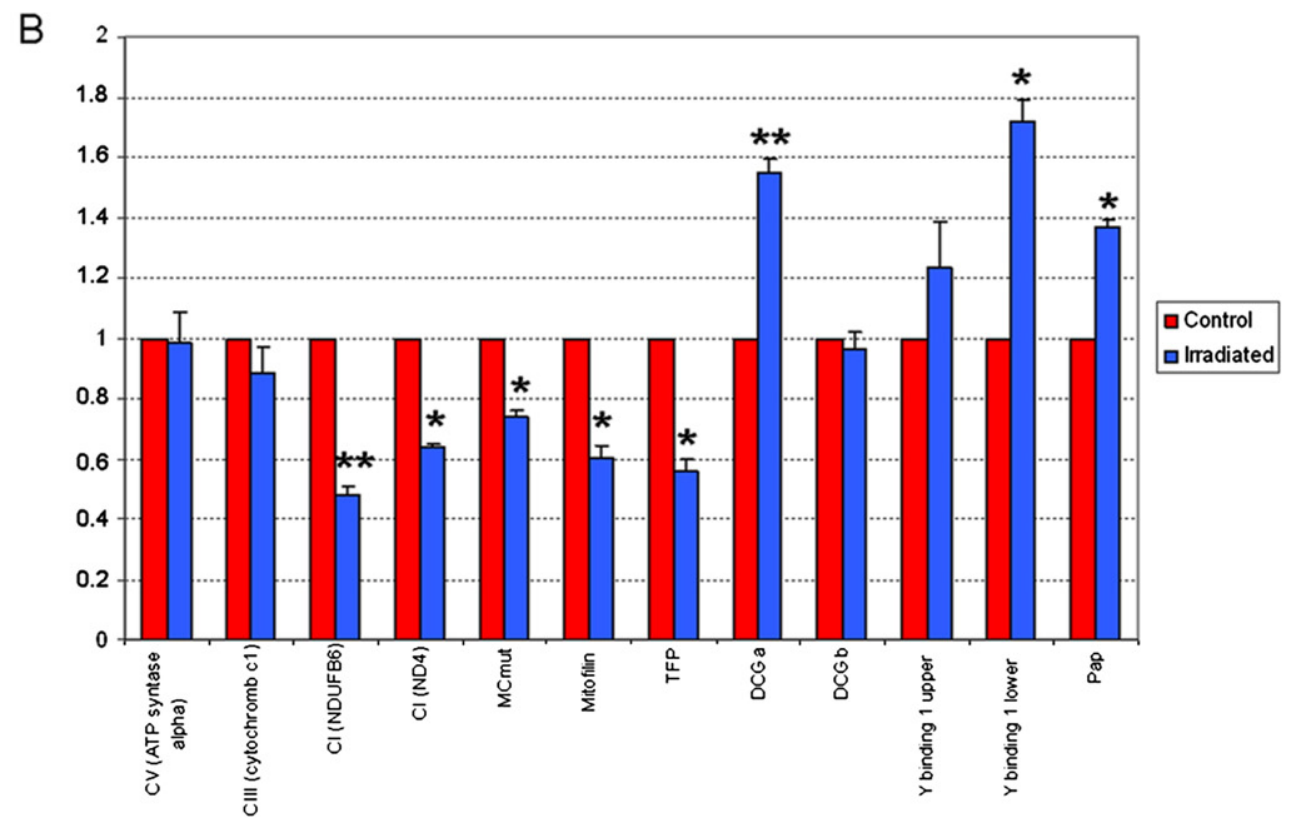

Fig. 3 - Immunoblot verification of differentially expressed proteins. (A) $25 \mu \mathrm{g}$ extracted proteins from control and irradiated FFPE hearts at $24 \mathrm{~h}$ after exposure were separated by $12 \%$ and 15\% SDS-PAGE and analysed by immunoblotting using a premixed cocktail antibody (OXPHOS) including one antibody against each mitochondrial complex: CI subunit NDUFB8, CII-30 kDa, CIII-Core protein 2, CIV subunit I and CV a subunit (a) and anti-NDUFB6 (b), anti-ND4 (c), anti-Methyl Coa mutase (MCmut) (d), anti-mitofilin (e), anti-three functional mitochondrial protein (TFP) (f), anti-dystroglycan alpha (DCG $\alpha$ ) (g) dystroglycan beta (DCG $\beta$ ) (h), anti-Y binding protein (Yb1) (i), and paxillin-associated protein (Pap) (j). The same amount of protein was used in all cases. The protein bands were quantified using ImageJ software by integration of all the pixel values in the band area after background correction and normalised to the tubulin alpha expression (k) (t-test; $\left.{ }^{*} p \leq 0.05,{ }^{* *} p \leq 0.01\right)$. In the case of multiple bands, the black arrow indicates the main band at the expected molecular weight corresponding to the full length protein. In the case of $\mathrm{Yb1}$, the star indicates the truncated form.Three biological replicates were used in all experiments. (B) Columns represent the average ratios of relative protein expression in control and irradiated samples. 
Dihydrolipoamide acetyltransferase is a catalytic component (component E2) of the pyruvate dehydrogenase complex, converting pyruvate to acetyl-CoA. E2 subunit controls both glycolysis and the tricarboxylic acid cycle [51]. We have previously reported radiation-induced alteration in both level and activity of pyruvate dehydrogenase E1 alpha in the cardiac mitochondria [22].

We suggest that the three main pathways found to be altered in this study, namely mitochondrial respiratory chain, lipid metabolism and pyruvate metabolism, are interactive. A significant reduction in mitochondrial respiratory capacity and subsequent cardiac oxidative capacity after heart failure, both with substrates of fatty acid and carbohydrate oxidation, has been described [38].

\subsection{Others}

Our data also show a significant radiation-induced increase in the abundance of dystroglycan in the cardiac tissue. Immunoblotting detected both dystroglycan isoforms, verifying the alteration observed by mass spectrometry. Despite the highly glycosylated status of dystroglycan alpha, antibody detection confirmed the increase of this subunit. Dystroglycan is a member of the dystrophin-associated protein complex in muscle [52] that functions as a transmembrane linkage between the extracellular matrix and the cytoskeleton [53]. Dystrophin-deficient mice exhibit slowly developing cardiomyopathy that can be accelerated by glutathione depletion, indicating its involvement in oxidative stress [54].

We found up-regulation of Y-box-binding protein 1 (YB-1), a member of DNA/RNA-binding nucleo-cytoplasmic shuttling protein family [55] which may be involved in damage recognition in the DNA repair pathway $[56,57]$. The YB-1 protein undergoes a proteasome-mediated cleavage under stress conditions in vivo that leads to an accumulation of the truncated protein in the nuclei of stressed cells [55]. Bieler et al. showed that radiation increases the nuclear YB-1 fraction in glioma cells [58]. In good agreement with these data, we detected a single peptide of YB-1 protein belonging to the truncated domain that is localised in the nucleus [55], suggesting stress-responsive alterations in the irradiated heart tissue. In accordance with the mass spectrometry data, immunoblotting analysis showed a moderate increase in the low molecular weight polypeptide presumably representing the truncated protein.

We found increased level of a Pap (paxillin associated protein), a multidomain protein composed of an Arf-GAP domain (ADPribosylation factor and GTPase-activating domain), an ankyrin homology region, a proline-rich region, and a C-terminal SH3 domain [59]. This protein binds to paxillin, an adaptor molecule in integrin signalling [60]. Ionising radiation is known to affect the phosphorylation status of paxillin and alter paxillin levels [61].

\section{Conclusions}

Our study shows that label-free proteomic approach enables to detect and quantify radiation-induced alterations in FFPE tissue. It indicates that archival tissue, that frequently is the only source of biomaterial available, plays a valuable role in retrospective molecular studies. This is particularly valid in cardiovascular diseases where additional collecting and sampling of fresh-frozen biomaterial is for ethical reasons cumbersome. We suggest that the three pathways found radiation-responsive in this study play an important role in the aetiology of radiation-induced cardiovascular disease.

\section{Acknowledgements}

This work was supported by a grant from the European Community's Seventh Framework Programme (EURATOM) contract no. 232628 (STORE). We acknowledge Dr. Steven E. Lipshultz for the valuable advice and discussions in the preparation of this manuscript. We thank Dr. Hakan Sarioglu, Sandra Helm and Waldemar Schneider for their technical assistance.

\section{Appendix A. Supplementary data}

Supplementary data to this article can be found online at doi:10.1016/j.jprot.2012.02.019.

\section{R E F E R E N C E S}

[1] Tapio S, Atkinson MJ. Molecular information obtained from radiobiological tissue archives: achievements of the past and visions of the future. Radiat Environ Biophys 2008;47:183-7.

[2] Tapio S, Hornhardt S, Gomolka M, Leszczynski D, Posch A, Thalhammer S, et al. Use of proteomics in radiobiological research: current state of the art. Radiat Environ Biophys 2010;49:1-4.

[3] Tapio S, Schofield PN, Adelmann C, Atkinson MJ, Bard JL, Bijwaard $\mathrm{H}$, et al. Progress in updating the European Radiobiology Archives. Int J Radiat Biol 2008;84:930-6.

[4] Hood BL, Conrads TP, Veenstra TD. Mass spectrometric analysis of formalin-fixed paraffin-embedded tissue: unlocking the proteome within. Proteomics 2006;6:4106-14.

[5] Nirmalan NJ, Harnden P, Selby PJ, Banks RE. Development and validation of a novel protein extraction methodology for quantitation of protein expression in formalin-fixed paraffin-embedded tissues using western blotting. J Pathol 2009;217:497-506.

[6] Nazarian J, Santi M, Hathout Y, Macdonald TJ. Protein profiling of formalin fixed paraffin embedded tissue: identification of potential biomarkers for pediatric brainstem glioma. Proteomics Clin Appl 2008;2:915-24.

[7] Tanca A, Addis MF, Pagnozzi D, Cossu-Rocca P, Tonelli R, Falchi $\mathrm{G}$, et al. Proteomic analysis of formalin-fixed, paraffin-embedded lung neuroendocrine tumor samples from hospital archives. J Proteomics 2011;74:359-70.

[8] Shi SR, Liu C, Balgley BM, Lee C, Taylor CR. Protein extraction from formalin-fixed, paraffin-embedded tissue sections: quality evaluation by mass spectrometry. J Histochem Cytochem 2006;54:739-43.

[9] Becker KF, Schott C, Hipp S, Metzger V, Porschewski P, Beck R, et al. Quantitative protein analysis from formalin-fixed tissues: implications for translational clinical research and nanoscale molecular diagnosis. J Pathol 2007;211:370-8.

[10] Fowler CB, Cunningham RE, O'Leary TJ, Mason JT. 'Tissue surrogates' as a model for archival formalin-fixed paraffin-embedded tissues. Lab Invest 2007;87:836-46. 
[11] Azimzadeh O, Barjaktarovic Z, Aubele M, Calzada-Wack J, Sarioglu H, Atkinson MJ, et al. Formalin-fixed paraffin-embedded (FFPE) proteome analysis using gel-free and gel-based proteomics. J Proteome Res 2010;9:4710-20.

[12] Metz B, Kersten GF, Hoogerhout P, Brugghe HF, Timmermans $\mathrm{HA}$, de Jong $\mathrm{A}$, et al. Identification of formaldehyde-induced modifications in proteins: reactions with model peptides. J Biol Chem 2004;279:6235-43.

[13] Xiao Z, Li G, Chen Y, Li M, Peng F, Li C, et al. Quantitative proteomic analysis of formalin-fixed and paraffin-embedded nasopharyngeal carcinoma using iTRAQ labeling, two-dimensional liquid chromatography, and tandem mass spectrometry. J Histochem Cytochem 2010;58:517-27.

[14] Ono A, Kumai T, Koizumi H, Nishikawa H, Kobayashi S, Tadokoro M. Overexpression of heat shock protein 27 in squamous cell carcinoma of the uterine cervix: a proteomic analysis using archival formalin-fixed, paraffin-embedded tissues. Hum Pathol 2009;40:41-9.

[15] Jain MR, Liu T, Hu J, Darfler M, Fitzhugh V, Rinaggio J, et al. Quantitative proteomic analysis of formalin fixed paraffin embedded oral HPV lesions from HIV patients. Open Proteomics J 2008;1:40-5.

[16] Donadio E, Giusti L, Cetani F, Da Valle Y, Ciregia F, Giannaccini $\mathrm{G}$, et al. Evaluation of formalin-fixed paraffin-embedded tissues in the proteomic analysis of parathyroid glands. Proteome Sci 2011;9:29.

[17] Ostasiewicz P, Zielinska DF, Mann M, Wisniewski JR. Proteome, phosphoproteome, and $\mathrm{N}$-glycoproteome are quantitatively preserved in formalin-fixed paraffin-embedded tissue and analyzable by high-resolution mass spectrometry. J Proteome Res 2010;9:3688-700.

[18] Hood BL, Darfler MM, Guiel TG, Furusato B, Lucas DA, Ringeisen BR, et al. Proteomic analysis of formalin-fixed prostate cancer tissue. Mol Cell Proteomics 2005;4:1741-53.

[19] Patel V, Hood BL, Molinolo AA, Lee NH, Conrads TP, Braisted JC, et al. Proteomic analysis of laser-captured paraffin-embedded tissues: a molecular portrait of head and neck cancer progression. Clin Cancer Res 2008;14:1002-14.

[20] Hauck SM, Dietter J, Kramer RL, Hofmaier F, Zipplies JK, Amann B, et al. Deciphering membrane-associated molecular processes in target tissue of autoimmune uveitis by label-free quantitative mass spectrometry. Mol Cell Proteomics 2010;9: 2292-305.

[21] Azimzadeh O, Scherthan H, Sarioglu H, Barjaktarovic Z, Conrad M, Vogt A, et al. Rapid proteomic remodeling of cardiac tissue caused by total body ionizing radiation. Proteomics 2011;11:3299-311.

[22] Barjaktarovic Z, Schmaltz D, Shyla A, Azimzadeh O, Schulz S, Haagen J, et al. Radiation-induced Signaling Results in Mitochondrial Impairment in Mouse Heart at 4 Weeks after Exposure to X-rays. PLoS One 2011;6:e27811.

[23] Thomas PD, Kejariwal A, Guo N, Mi H, Campbell MJ, Muruganujan A, et al. Applications for protein sequence-function evolution data: mRNA/protein expression analysis and coding SNP scoring tools. Nucleic Acids Res 2006;34:W645-50.

[24] Huang da W, Sherman BT, Lempicki RA. Systematic and integrative analysis of large gene lists using DAVID bioinformatics resources. Nat Protoc 2009;4:44-57.

[25] Wu J, Liu W, Bemis A, Wang E, Qiu Y, Morris EA, et al. Comparative proteomic characterization of articular cartilage tissue from normal donors and patients with osteoarthritis. Arthritis Rheum 2007;56:3675-84.

[26] D’Eustachio P. Reactome knowledgebase of human biological pathways and processes. Methods Mol Biol 2011;694:49-61.

[27] Addis MF, Tanca A, Pagnozzi D, Crobu S, Fanciulli G, Cossu-Rocca $P$, et al. Generation of high-quality protein extracts from formalin-fixed, paraffin-embedded tissues. Proteomics 2009;9: 3815-23.
[28] Azizova TV, Muirhead CR, Druzhinina MB, Grigoryeva ES, Vlasenko EV, Sumina MV, et al. Cardiovascular diseases in the cohort of workers first employed at Mayak PA in 1948-1958. Radiat Res 2010;174:155-68.

[29] Tukenova M, Guibout C, Oberlin O, Doyon F, Mousannif A, Haddy $\mathrm{N}$, et al. Role of cancer treatment in long-term overall and cardiovascular mortality after childhood cancer. J Clin Oncol 2010;28:1308-15.

[30] Shimizu Y, Kodama K, Nishi N, Kasagi F, Suyama A, Soda M, et al. Radiation exposure and circulatory disease risk: Hiroshima and Nagasaki atomic bomb survivor data, 1950-2003. BMJ 2010;340:b5349.

[31] Kim GJ, Chandrasekaran K, Morgan WF. Mitochondrial dysfunction, persistently elevated levels of reactive oxygen species and radiation-induced genomic instability: a review. Mutagenesis 2006;21:361-7.

[32] Kim GJ, Fiskum GM, Morgan WF. A role for mitochondrial dysfunction in perpetuating radiation-induced genomic instability. Cancer Res 2006;66:10377-83.

[33] Miller JH, Jin S, Morgan WF, Yang A, Wan Y, Aypar U, et al. Profiling mitochondrial proteins in radiation-induced genome-unstable cell lines with persistent oxidative stress by mass spectrometry. Radiat Res 2008;169:700-6.

[34] Wyrobek AJ, Manohar CF, Krishnan VV, Nelson DO, Furtado MR, Bhattacharya MS, et al. Low dose radiation response curves, networks and pathways in human lymphoblastoid cells exposed from 1 to $10 \mathrm{cGy}$ of acute gamma radiation. Mutat Res 2011;722:119-30.

[35] Paradies G, Petrosillo G, Paradies V, Ruggiero FM. Oxidative stress, mitochondrial bioenergetics, and cardiolipin in aging. Free Radic Biol Med 2010;48:1286-95.

[36] Gieffers C, Korioth F, Heimann P, Ungermann C, Frey J. Mitofilin is a transmembrane protein of the inner mitochondrial membrane expressed as two isoforms. Exp Cell Res 1997;232: 395-9.

[37] John GB, Shang Y, Li L, Renken C, Mannella CA, Selker JM, et al. The mitochondrial inner membrane protein mitofilin controls cristae morphology. Mol Biol Cell 2005;16:1543-54.

[38] Bugger H, Schwarzer M, Chen D, Schrepper A, Amorim PA, Schoepe M, et al. Proteomic remodelling of mitochondrial oxidative pathways in pressure overload-induced heart failure. Cardiovasc Res 2010;85:376-84.

[39] Razeghi P, Young ME, Alcorn JL, Moravec CS, Frazier OH, Taegtmeyer H. Metabolic gene expression in fetal and failing human heart. Circulation 2001;104:2923-31.

[40] Stanley WC, Recchia FA, Lopaschuk GD. Myocardial substrate metabolism in the normal and failing heart. Physiol Rev 2005;85:1093-129.

[41] Osorio JC, Stanley WC, Linke A, Castellari M, Diep QN, Panchal AR, et al. Impaired myocardial fatty acid oxidation and reduced protein expression of retinoid X receptor-alpha in pacing-induced heart failure. Circulation 2002;106: 606-12.

[42] Purushothaman S, Renuka Nair R, Harikrishnan VS, Fernandez AC. Temporal relation of cardiac hypertrophy, oxidative stress, and fatty acid metabolism in spontaneously hypertensive rat. Mol Cell Biochem 2011;351:59-64.

[43] Rector RS, Payne RM, Ibdah JA. Mitochondrial trifunctional protein defects: clinical implications and therapeutic approaches. Adv Drug Deliv Rev 2008;60:1488-96.

[44] Matern D, Strauss AW, Hillman SL, Mayatepek E, Millington DS, Trefz FK. Diagnosis of mitochondrial trifunctional protein deficiency in a blood spot from the newborn screening card by tandem mass spectrometry and DNA analysis. Pediatr Res 1999;46:45-9.

[45] Spiekerkoetter U, Wood PA. Mitochondrial fatty acid oxidation disorders: pathophysiological studies in mouse models. J Inherit Metab Dis 2010;33:539-46. 
[46] Chandler RJ, Zerfas PM, Shanske S, Sloan J, Hoffmann V, DiMauro S, et al. Mitochondrial dysfunction in mut methylmalonic acidemia. FASEB J 2009;23:1252-61.

[47] Hayasaka K, Metoki K, Satoh T, Narisawa K, Tada K, Kawakami T, et al. Comparison of cytosolic and mitochondrial enzyme alterations in the livers of propionic or methylmalonic acidemia: a reduction of cytochrome oxidase activity. Tohoku J Exp Med 1982;137:329-34.

[48] Doenst T, Pytel G, Schrepper A, Amorim P, Farber G, Shingu Y, et al. Decreased rates of substrate oxidation ex vivo predict the onset of heart failure and contractile dysfunction in rats with pressure overload. Cardiovasc Res 2010;86:461-70.

[49] Akki A, Smith K, Seymour AM. Compensated cardiac hypertrophy is characterised by a decline in palmitate oxidation. Mol Cell Biochem 2008;311:215-24.

[50] Barger PM, Kelly DP. PPAR signaling in the control of cardiac energy metabolism. Trends Cardiovasc Med 2000;10:238-45.

[51] Sun Y, Deng X, Li W, Yan Y, Wei H, Jiang Y, et al. Liver proteome analysis of adaptive response in rat immediately after partial hepatectomy. Proteomics 2007;7:4398-407.

[52] Williamson RA, Henry MD, Daniels KJ, Hrstka RF, Lee JC, Sunada Y, et al. Dystroglycan is essential for early embryonic development: disruption of Reichert's membrane in Dag1-null mice. Hum Mol Genet 1997;6:831-41.

[53] Kanagawa M, Nishimoto A, Chiyonobu T, Takeda S, Miyagoe-Suzuki Y, Wang F, et al. Residual laminin-binding activity and enhanced dystroglycan glycosylation by LARGE in novel model mice to dystroglycanopathy. Hum Mol Genet 2009;18:621-31.

[54] Khouzami L, Bourin MC, Christov C, Damy T, Escoubet B, Caramelle P, et al. Delayed cardiomyopathy in dystrophin deficient mdx mice relies on intrinsic glutathione resource. Am J Pathol 2010;177:1356-64.

[55] Sorokin AV, Selyutina AA, Skabkin MA, Guryanov SG, Nazimov IV, Richard C, et al. Proteasome-mediated cleavage of the Y-box-binding protein 1 is linked to DNA-damage stress response. EMBO J 2005;24:3602-12.

[56] Marenstein DR, Ocampo MT, Chan MK, Altamirano A, Basu AK, Boorstein RJ, et al. Stimulation of human endonuclease III by Y box-binding protein 1 (DNA-binding protein B). Interaction between a base excision repair enzyme and a transcription factor. J Biol Chem 2001;276:21242-9.

[57] Izumi $H$, Imamura $T$, Nagatani $G$, Ise $T$, Murakami $T$, Uramoto $\mathrm{H}$, et al. $\mathrm{Y}$ box-binding protein- 1 binds preferentially to single-stranded nucleic acids and exhibits $3^{\prime} \rightarrow>5^{\prime}$ exonuclease activity. Nucleic Acids Res 2001;29:1200-7.

[58] Bieler A, Mantwill K, Holzmuller R, Jurchott K, Kaszubiak A, Stark $\mathrm{S}$, et al. Impact of radiation therapy on the oncolytic adenovirus d1520: implications on the treatment of glioblastoma. Radiother Oncol 2008;86:419-27.

[59] Andreev J, Simon JP, Sabatini DD, Kam J, Plowman G, Randazzo PA, et al. Identification of a new Pyk2 target protein with Arf-GAP activity. Mol Cell Biol 1999;19:2338-50.

[60] Kondo A, Hashimoto S, Yano H, Nagayama K, Mazaki Y, Sabe H. A new paxillin-binding protein, PAG3/Papalpha/KIAA0400, bearing an ADP-ribosylation factor GTPase-activating protein activity, is involved in paxillin recruitment to focal adhesions and cell migration. Mol Biol Cell 2000;11:1315-27.

[61] Beinke C, Van Beuningen D, Cordes N. Ionizing radiation modules of the expression and tyrosine phosphorylation of the focal adhesion-associated proteins focal adhesion kinase (FAK) and its substrates p130cas and paxillin in A549 human lung carcinoma cells in vitro. Int J Radiat Biol 2003;79:721-31. 